\title{
CONTEÚDOS DE APRENDIZAGEM PRESENTES EM UM MATERIAL EDUCATIVO IMPRESSO SOBRE COMBATE À DENGUE
}

\author{
LEARNING CONTENT IN PRINTED EDUCATIONAL MATERIALS AGAINST \\ DENGUE
}

\author{
Nauristela Ferreira Paniago Damasceno ${ }^{1}$ \\ Natália Müller ${ }^{2}$ \\ Antônio Sales ${ }^{3}$ \\ Cibele de Moura Sales ${ }^{4}$ \\ Cássia Barbosa Reis ${ }^{5}$
}

\begin{abstract}
Resumo
Este artigo analisou os conteúdos de aprendizagem inseridos em um material educativo impresso, no formato história em quadrinhos (HQ), produzido para a campanha de combate à dengue em um estado brasileiro. Tratou-se de uma pesquisa documental, caracterizada pela análise de conteúdo realizada a partir da tipologia proposta por Zabala. A análise incluiu o texto e as figuras da cartilha, na sequência de leitura. Foi possível perceber a predominância, tanto no texto como nas figuras, dos conteúdos procedimentais e atitudinais. Embora os conteúdos atitudinais identificados estejam inseridos em um contexto de mobilização e protagonismo da comunidade, observou-se que também estão presentes conteúdos que remetem ao ideário da Educação Sanitária, como o reforço às mudanças de comportamento e hábitos de higiene. Percebeu-se ainda a necessidade de outros estudos, longitudinais, para que se possa investigar a capacidade desse tipo de material educativo, na prevenção da dengue.
\end{abstract}

\footnotetext{
${ }^{1}$ A autora é mestranda do Programa de Pós-graduação Stricto Sensu Ensino em Saúde, Mestrado Profissional (PPGES) da Universidade Estadual de Mato Grosso do Sul (UEMS). E-mail: naurapsi @ hotmail.com

2 A autora é mestranda do Programa de Pós-graduação Stricto Sensu Ensino em Saúde, Mestrado Profissional (PPGES).E-mail: nat_muller@hotmail.com

${ }^{3} \mathrm{O}$ autor é doutor em Educação pela Universidade Federal de Mato Grosso do Sul (UFMS). Atualmente é professor efetivo da Universidade Estadual de Mato Grosso do Sul (UEMS) e docente do Programa de Pósgraduação Stricto Sensu Ensino em Saúde, Mestrado Profissional (PPGES). E-mail: profesales2@gmail.com ${ }^{4}$ A autora é doutora em Ciências da Saúde pela Universidade de Brasília (UnB). Atualmente é professora efetiva da Universidade Estadual de Mato Grosso do Sul (UEMS) e docente do Programa de Pós-graduação Stricto Sensu Ensino em Saúde, Mestrado Profissional (PPGES). E-mail: cibele_saless@icloud.com

5 A autora é doutora em Doenças Infecciosas e Parasitárias pela Universidade Federal de Mato Grosso do Sul (UFMS). Atualmente é professora efetiva da Universidade Estadual de Mato Grosso do Sul (UEMS) e docente do Programa de Pós-graduação Stricto Sensu Ensino em Saúde, Mestrado Profissional (PPGES). E-mail: cassia@uems.br
} 
Palavras-chave: Educação em saúde. Conteúdos de aprendizagem. Material educativo impresso. Dengue.

\begin{abstract}
This article analyzed the learning content inserted into the printed educational material in comics (HQ), produced for the campaign against dengue in a Brazilian state. This was a documentary research, characterized by content analysis from the typology proposed by Zabala. The analysis included the text and figures of the booklet, following readings. It could be observed that predominated both in text and in figures, the procedural and attitudinal contents. Although attitudinal contents identified in the analysis are inserted in a context of community mobilization and leadership, it was observed there is content that refer to the ideology of sanitary education, as reinforcement to change behavior and hygiene habits. It was perceived the need for studies, longitudinal, so that we can investigate the ability of this type of educational materials, in the prevention of dengue.
\end{abstract}

Keywords: Health education. Learning content. Printed educational material. Dengue.

\title{
INTRODUÇÃO
}

A dengue é considerada um dos principais problemas de saúde pública no mundo acometendo, anualmente, segundo estimativas da Organização Mundial de Saúde, 50 milhões de pessoas (OMS, 2010). No Brasil, em 2015, foram registrados 1.125 .955 casos prováveis de dengue até a semana epidemiológica 23 - período compreendido entre 04/01/15 e 13/06/15 sendo que no mesmo período de 2014 foram registrados 444.614 casos prováveis. (BRASIL, 2015).

As ações do Ministério da Saúde, conforme descritas nas Diretrizes Nacionais para Prevenção e Controle de Epidemias de Dengue (BRASIL, 2009) e no Plano de Contingência Nacional para Epidemias de Dengue (BRASIL, 2015), incluem várias estratégias de combate à doença incluindo estratégias de comunicação e mobilização da população. Entre essas estratégias estão contemplados os materiais educativos impressos, os quais, geralmente, são elaborados com objetivo de informar a comunidade sobre a importância do controle populacional do mosquito Aedes aegypti, principal vetor da doença.

As ações de comunicação e mobilização são muito relevantes na saúde pública, uma vez que, nessa área, a participação ativa da comunidade é essencial (LEFÈVRE et al, 2007). Dessa forma, muito se tem investido na Educação em Saúde com finalidade de prevenção de 
doenças e promoção de saúde, buscando integrar os conhecimentos científicos à vida cotidiana das pessoas, através de diferentes práticas educativas, entre elas, a elaboração de materiais impressos. (REIS, 2006).

Assis, Pimenta e Schall (2013) reforçam que os materiais educativos impressos são desenvolvidos com diferentes objetivos, destacando-se, na área de saúde pública, a divulgação de informações consideradas importantes para a prevenção ou controle de agravos, além da promoção da saúde. De fato, a utilização desse tipo de material é prática comum no Sistema Único de Saúde (SUS); entretanto, sua relevância depende dos princípios e das formas de comunicação envolvidos nos processos de elaboração. (REBERTE; HOGA; GOMES, 2012).

Dessa forma, as Diretrizes Nacionais para Prevenção e Controle de Epidemias de Dengue (BRASIL, 2009, p. 89), orientam, superficialmente, que a produção de material educativo impresso deve ocorrer "[...] de acordo com o conhecimento, a linguagem e a realidade regionais". Zombini e Pelicioni (2011) acrescentam que um material educativo bem produzido deve atender às expectativas e às necessidades da população alvo. Recomendam ainda a elaboração de materiais multimídia, capazes de tornar a atividade desenvolvida mais dinâmica e criativa, despertando o interesse e a participação ativa dos envolvidos.

Entretanto, alguns autores (MIALHE; SILVA, 2008; KELLY-SANTOS; MONTEIRO; ROZEMBERG, 2009; ZOMBINI; PELICIONI, 2011; FREITAS; REZENDE FILHO, 2011; ARMINDO; DINIZ; SCHALL, 2011; ASSIS; PIMENTA; SCHALL, 2013) apontam que o material educativo impresso desenvolvido em diversos contextos da área de saúde, não atinge o seu objetivo devido não apenas à divergência entre o que se pretende informar e o que o público alvo considera relevante, mas também pela predominância de uma linguagem técnica, verticalizada, linear e prescritiva.

Considerando a importância dos materiais educativos impressos nas práticas de educação em saúde e em vista da escassez de estudos que observam os conteúdos de aprendizagem inseridos nos materiais educativos sobre a dengue, propõem-se, a partir da tipologia sugerida por Zabala (2008), a análise dos conteúdos de aprendizagem inseridos em uma cartilha, no formato de história em quadrinhos, elaborada para a campanha de combate à dengue, em um estado brasileiro. 


\section{EDUCAÇÃO EM SAÚDE}

De acordo com Reis et al (2013) a Educação em Saúde tem suas origens, no Brasil, na Educação Sanitária, na década de 1920, caracterizada pelo modelo tradicional de educação, em que o educador é o detentor do conhecimento, o qual deve ser transmitido aos educandos que, por usa vez, deverão absorver esses conteúdos para reproduzi-los. Nesse contexto, as ações educativas em saúde reforçavam a importância dos hábitos de higiene no enfrentamento dos problemas sanitários do país e inseriram, além dos serviços de saúde, na escola, principalmente na escola primária, para o ensino, em sala de aula, de noções essenciais de higiene.

Para Rocha (2003) o foco na escola primária decorreu da noção de plasticidade do cérebro infantil em contraste com a de progressivo enrijecimento do adulto, de modo que os esforços para moldar os hábitos de higiene que levariam à saúde, deveriam concentrar-se na criança em idade escolar.

Por volta dos anos 1950, as concepções tradicionais começaram a dar lugar a ideias como a participação ativa dos sujeitos na promoção da saúde, o trabalho em comunidade e a participação comunitária (RENOVATO; BAGNATO, 2010). A partir da década de 1970 essas ideias se consolidaram por meio das influências de Paulo Freire e outros pensadores críticos - relacionados com a Educação Popular em Saúde e com a educação de adultos - e também da criação do Sistema Único de Saúde - SUS, fazendo com que as mudanças comportamentais - ou seja, o foco na alteração dos hábitos de higiene - deixasse de ser a principal estratégia, abrindo espaço para ações educativas participativas que considerassem o conhecimento dos educandos e o contexto real em que estavam inseridos. (REIS et al., 2013).

Segundo Vasconcelos (2004) a educação em saúde configura-se como um campo de prática e de conhecimento da saúde ocupando-se com a criação de vínculos entre os serviços de saúde e o pensar e fazer cotidiano da população, os quais ocorrem através dos grandes meios de comunicação de massa e também da convivência cotidiana entre os profissionais que atuam nesses serviços e a população, usuária dos mesmos. Principalmente na perspectiva da comunicação de massa, observa-se que os vídeos, os folhetos, os panfletos, as cartilhas e 
outros materiais, são valiosos instrumentos no campo da educação em saúde, pelo caráter informativo que possuem. (NOGUEIRA; MODENA; SCHALL, 2009).

Entretanto, segundo Assis, Pimenta e Schall (2013) é importante considerar, na elaboração desses materiais educativos, a abordagem pedagógica mais adequada aos objetivos e ao público alvo. Isso porque cada abordagem pedagógica contempla uma visão de mundo, de sujeito, de desenvolvimento e de aprendizagem. Nesse sentido, no que se refere à educação em saúde, é relevante pensar em abordagens que privilegiem a construção do conhecimento pela população, superando a ênfase na transmissão ou reprodução de conteúdo técnico e favorecendo a ação de um sujeito concebido como capaz de interagir ativamente em sua realidade, refletindo sobre seu papel no cuidado com sua própria vida e com o ambiente, além de estimular um intercâmbio horizontal de conhecimentos entre população e profissionais de saúde.

\section{HISTÓRIA EM QUADRINHOS}

Por definição as histórias em quadrinhos (HQ) são sequências de imagens em quadros criados proporcionalmente, retratando pequenas histórias, acompanhadas por balões que representam diálogos de personagens, de modo a favorecer a sua compreensão (PEREIRA, 2010).

Atualmente as HQs, além da função de entretenimento, também têm um caráter informativo, visto que, a partir da década de 1980, deu-se maior importância ao uso dos quadrinhos como instrumento de aprendizagem e de divulgação de conteúdos científicos, sendo utilizadas por organizações de pesquisa como a Empresa Brasileira de Pesquisa Agropecuária (Embrapa) com o objetivo de divulgar os conhecimentos produzidos na instituição, para poder atingir, principalmente, alunos de ensino médio. (CABELLO; ROCQUE; SOUZA 2010).

Corroborando o novo papel das HQ na educação, o Ministério da Educação - que através do Programa Nacional de Biblioteca da Escola, compra livros diretamente das editoras para equipar as bibliotecas públicas das redes federal, estadual e municipal de ensino - passou a incluir, desde 2006, as HQ entre os materiais pedagógicos adquiridos. (BRASIL, 2014). 
Pelo exposto, percebe-se que os quadrinhos passaram a ser utilizados com diferentes objetivos pedagógicos. Caruso e Silveira (2009), em artigo sobre como utilizar as HQ para trabalhar conceitos de ciências, saúde, história, sociologia, linguagem, com jovens de escolas públicas de ensino médio do Rio de Janeiro, propõem uma classificação dos quadrinhos quanto a sua natureza. Considerando os objetivos deste estudo são especialmente relevantes os conteúdos relacionados à formação da cidadania, os quais incluem questões e conceitos avaliados como indispensáveis para a alfabetização científica ou para a formação básica do cidadão, abrangendo noções relacionadas à prevenção de doenças, à saúde pública, à preservação do ambiente, entre outras. (CARUSO; SILVEIRA, 2009).

As cartilhas em formato de HQ voltadas para a área da saúde trazem conteúdos que também poderiam receber essa mesma classificação. Além disso, geralmente esse tipo de material educativo, segundo Mendonça (2008) apresenta uma trama que se constitui por situações de perigo, envolvendo personagens que representam heróis e vilões, para divulgar informações sobre a prevenção ou o tratamento de doenças específicas. A mesma autora defende a natureza lúdica das HQ, normalmente associadas à diversão e a uma leitura descompromissada, supostamente mais leve e de fácil entendimento. Refere também que o enredo facilita a leitura ao expor os fatos numa sequência que integra texto e imagem significativamente e considera que as personagens e as situações retratadas, da forma como são introduzidas, possibilitam um processo de identificação para os leitores, facilitando a compreensão das informações. (MENDONÇA, 2008).

Ainda no campo da saúde, há alguns estudos que avaliaram positivamente a utilização de material educativo, no formato de história em quadrinhos. Um desses estudos (CABELLO; ROCQUE; SOUZA, 2010) objetivou divulgar conceitos acerca da hanseníase para préadolescentes de $5^{\mathrm{a}}$ e $6^{\mathrm{a}}$ séries do ensino fundamental e constatou que é possível ensinar ciência fazendo uso das HQs como auxiliares na educação. Kawamoto e Campos (2014) realizaram uma pesquisa com objetivo de elaborar e avaliar uma história em quadrinhos intitulada "Corpo humano" para estudantes do $5^{\circ}$ ano do Ensino Fundamental. As autoras apontaram que as HQ foram válidas como recurso didático complementar e observaram que esse tipo de material pedagógico 
envolve o aluno, possibilitando que o aprendizado seja diferenciado: o aluno aprende o conteúdo, desenvolve a capacidade criativa, pois a integração entre a realidade e a fantasia é favorecida, fazendo com que haja um 'mergulho' dos estudantes no contexto da história, e se familiarizando e se apropriando da situação e do conhecimento disponibilizado pelo material. (KAWAMOTO; CAMPOS, 2014, p. 156).

Mendonça (2008) lembra que, no caso das campanhas de educação em saúde, ter acesso às informações é um direito de todos e que atender às necessidades dos usuários dos serviços de saúde implica utilizar diferentes estratégicas que facilitem a apropriação dos conhecimentos científicos e o acesso às políticas públicas de saúde. Dessa forma, as HQ podem ser um recurso valioso, desde que sua utilização seja planejada, considerando a realidade do público alto e a adequação dos conteúdos abordados.

\section{CONTEÚDOS DE APRENDIZAGEM}

A tipologia dos conteúdos de aprendizagem proposta por Zabala (2008) os classifica em factuais, conceituais, procedimentais e atitudinais. $\mathrm{O}$ autor adverte que o objetivo de compartimentar os tipos de conteúdo é facilitar a compreensão sobre como ocorre o processo da aprendizagem. Entretanto, ele ressalta que a linha divisória entre um conteúdo e outro é muito sutil e confusa, visto que, um conteúdo sempre está associado e será aprendido junto com demais, atualizando, comparando, identificando diferenças e semelhanças, podendo potencializar uma aprendizagem significativa dos conhecimentos apresentados.

Para o autor, os conteúdos factuais se referem ao conhecimento produzido a partir da aprendizagem de fatos, acontecimentos, situações, dados e fenômenos concretos, singulares, descritivos que serão memorizados pelo aluno através, por exemplo, de repetição verbal, fazendo com que sejam reproduzidos fielmente. Os conceitos seriam os termos abstratos, os quais, para aprendizagem, necessitariam de compreensão; eles compreendem, segundo o autor, um conjunto de fatos, objetos ou símbolos que têm características comuns e podem ser tratados juntamente com os princípios, enquanto mudanças que se produzem num fato, objeto ou situação em relação a outros, descrevendo relações de causa-efeito ou de correlação. $\mathrm{O}$ conteúdo procedimental, para Zabala (2008) engloba as regras, as técnicas, os métodos, as destrezas ou habilidades, as estratégias, os procedimentos executados com um objetivo específico. Já os conteúdos atitudinais, segundo o autor, agrupam valores, atitudes e normas. 
Uma vez que a análise da cartilha baseia-se na tipologia de conteúdos de aprendizagem proposta por Zabala (2008) é importante considerar alguns pressupostos do autor, os quais também podem ser relevantes para as práticas educativas em saúde : a educação tem valorizado alguns conhecimentos e objetivos em detrimento de outros; “[...] por trás de qualquer intervenção pedagógica consciente se escondem uma análise sociológica e uma tomada de posição que sempre é ideológica" (ZABALA, 2008, p. 29); e se analisarmos uma unidade didática é possível conhecer os conteúdos que são trabalhados e avaliar se o que se propõe está de acordo com os objetivos propostos.

\section{MÉTODO}

Considerando-se a relevância da dengue para a saúde pública e a importância da mobilização popular no combate ao mosquito, buscou-se analisar os conteúdos de aprendizagem incluídos em um material educativo sobre a dengue elaborado para o público infantil, no formato de HQ. Trata-se de um estudo documental, caracterizado pela análise de conteúdo, sendo que as categorias de análise foram constituídas a partir da tipologia dos conteúdos de aprendizagem, proposta por Zabala (2008). A discussão fundamentou-se na literatura sobre a Educação em Saúde e no uso das HQ como material educativo impresso.

O material educativo impresso escolhido foi uma cartilha elaborada, em 2008, pelo Governo do Estado do Rio de Janeiro, em uma parceria entre a Secretaria de Estado de Saúde e Defesa Civil e a Secretaria de Estado de Educação. Para elaboração da HQ foi convidado o cartunista Ziraldo, criador do Menino Maluquinho, personagem principal da cartilha, que já havia participado de campanha anterior, também voltada ao público infantil. O título da cartilha analisada é "Maluquinhos Contra a Dengue 2", possui 24 páginas, foi elaborada em formato de gibi e distribuída nas escolas públicas do Rio de Janeiro. Esse material também possui uma versão digitalizada, a qual está disponível no site do Governo do Estado do Rio de Janeiro (RIO DE JANEIRO, 2008).

$\mathrm{Na}$ análise dos conteúdos de aprendizagem inseridos no material educativo foi considerado o texto (incluindo a apresentação da cartilha e diálogos entre as personagens da história em quadrinhos) e também as figuras. Esses dois elementos foram analisados quadro a 
quadro de acordo com a sequência em que é realizada a leitura da HQ, ou seja, de cima para baixo e da esquerda para a direita.

\section{RESULTADOS E DISCUSSÃO}

Para ilustrar o percurso percorrido para identificar os conteúdos de aprendizagem inseridos na cartilha, a figura 1 e o quadro 1 apresentam alguns exemplos de texto (diálogos), de figuras, dos conteúdos identificados (explícitos ou implícitos), de sua classificação segundo a tipologia sugerida por Zabala (2008) e da justificativa para a classificação.

Figura 1 - Convite e respectiva justificativa para a união ao combate à dengue

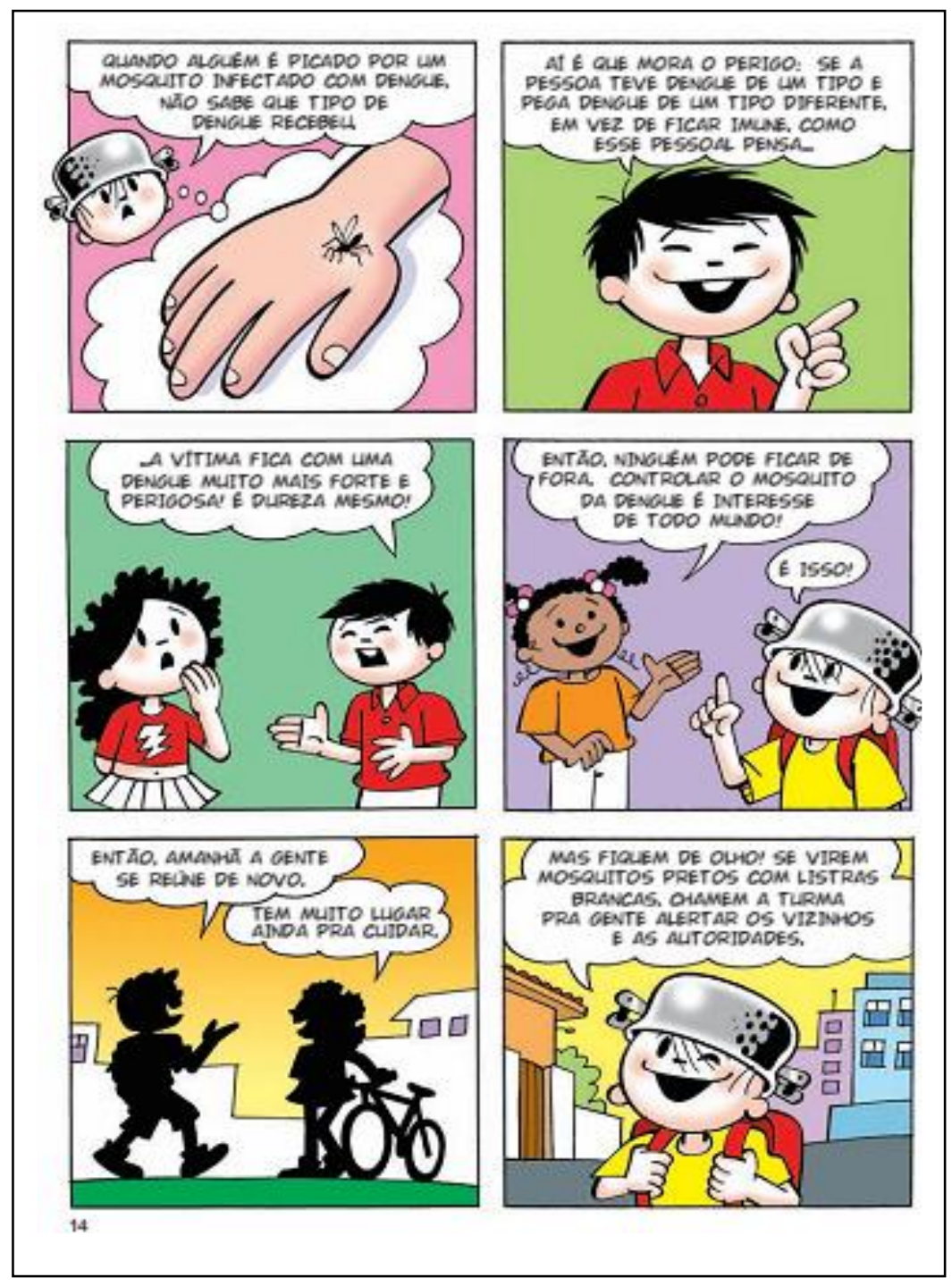

Fonte: Rio de Janeiro (2008, p.14) 


\section{Quadro 1- Exemplo de identificação dos conteúdos de aprendizagem da cartilha}

\begin{tabular}{|c|c|c|c|}
\hline Local & Conteúdos explícitos ou implícitos & $\begin{array}{l}\text { Tipo de } \\
\text { conteúdo }\end{array}$ & Justificativa \\
\hline \multirow{3}{*}{$\begin{array}{l}\text { P. } 14, \\
\text { quadros } \\
1 \text { a } 4\end{array}$} & $\begin{array}{l}\text { Aponta que devido a compreensão } \\
\text { equivocada, algumas pessoas } \\
\text { acreditam que ficaram imunes à } \\
\text { dengue e deixam de fazer a prevenção, } \\
\text { aumento o risco para a saúde de toda a } \\
\text { comunidade. Reforça a mobilização de } \\
\text { todos na prevenção. }\end{array}$ & Atitudinal & $\begin{array}{l}\text { Sugere a atuação de um grupo de } \\
\text { pessoas em comportamento não } \\
\text { valorizado na comunidade (deixar } \\
\text { de fazer a prevenção) e reforça os } \\
\begin{array}{l}\text { comportamentos valorizados } \\
\text { (comprometimento, cooperação, } \\
\text { prevenção). }\end{array}\end{array}$ \\
\hline & $\begin{array}{l}\text { Esclarece relação equivocada feita por } \\
\text { membros da comunidade e apresenta o } \\
\text { conceito correto (possibilidade de } \\
\text { agravar o quadro da doença em caso } \\
\text { de nova contaminação). }\end{array}$ & Conc & $\begin{array}{l}\text { Esclarecimento de conceito que } \\
\text { pode estar sendo compreendido de } \\
\text { forma equivocada por membros da } \\
\text { comunidade. }\end{array}$ \\
\hline & $\begin{array}{l}\text { Há mais de um tipo de dengue e o } \\
\text { quadro da doença é mais grave se a } \\
\text { pessoa adoecer, pela segunda vez, só } \\
\text { que por um tipo diferente do primeiro. }\end{array}$ & Factual & $\begin{array}{l}\text { Conhecimento de um fenômeno } \\
\text { concreto (tipos de dengue e } \\
\text { agravamento do quadro em caso de } \\
\text { contaminação por mais de um tipo } \\
\text { de dengue). }\end{array}$ \\
\hline \multirow{3}{*}{$\begin{array}{l}\text { P. } 14 \\
\text { quadros } \\
5 \text { e } 6\end{array}$} & $\begin{array}{l}\text { Continuidade da prevenção, estado de } \\
\text { alerta do grupo para mobilizar demais } \\
\text { membros/segmentos da comunidade. }\end{array}$ & Atitudinal & 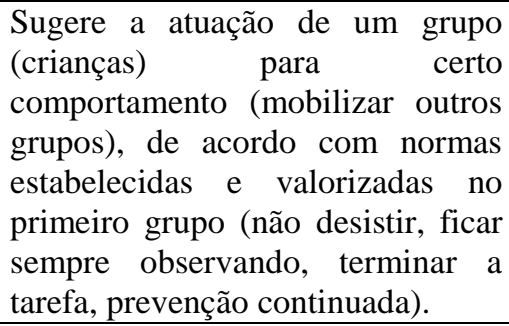 \\
\hline & $\begin{array}{l}\text { Reforça a continuidade das ações de } \\
\text { prevenção, o comportamento de alerta } \\
\text { e estabelece o que deve ser feito } \\
\text { (chamar outros membros do grupo } \\
\text { para que esse alerte outros segmentos } \\
\text { da comunidade). }\end{array}$ & Procedimental & 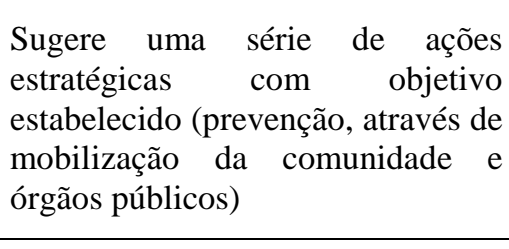 \\
\hline & $\begin{array}{l}\text { Reforça qual o mosquito deve ser } \\
\text { combatido (preto com listras brancas). }\end{array}$ & Factual & $\begin{array}{l}\text { Reforça conhecimento concreto } \\
\text { (descrição/tipo do mosquito). }\end{array}$ \\
\hline
\end{tabular}

Esse processo de análise, conforme indicado no método, foi realizado, quadro a quadro, em toda a cartilha, considerando texto e figuras, resultando no quadro 2 , que apresenta a classificação geral dos conteúdos de aprendizagem inseridos no material educativo avaliado. 
Quadro 2 - Classificação geral dos conteúdos de aprendizagem da cartilha

\begin{tabular}{|l|c|c|c|c|}
\hline \multicolumn{1}{|c|}{ Conteúdos } & Texto & Figuras & Total & \% \\
\hline Factual & 3 & 1 & 4 & 4 \\
\hline Conceitual & 20 & 4 & 24 & 26 \\
\hline Atitudinal & 26 & 10 & 36 & 38 \\
\hline Procedimental & 21 & 9 & 30 & 32 \\
\hline
\end{tabular}

Os conteúdos factuais, pouco valorizados na cartilha, contemplaram uma figura do mosquito da dengue picando a mão de uma pessoa e, no texto, os tipos de dengue e a descrição do mosquito. No que se refere aos conteúdos conceituais, podemos citar o uso de relações de causa e efeito ou de correlação, como a ideia de que há uma relação entre a prevenção continuada e a diminuição de casos de dengue e a de que todos os lugares com água empoçada podem se tornar um foco de proliferação do mosquito. Os conteúdos atitudinais foram inseridos, principalmente, com objetivo de fomentar a participação comunitária e reforçar os comportamentos valorizados na campanha, como manter o quintal limpo e mobilizar-se na manutenção de áreas coletivas como as praças. Já os conteúdos procedimentais enfocaram as ações específicas de combate ao mosquito, como encher o prato das plantas de areia, virar as garrafas, cobrir os pneus.

$\mathrm{Na}$ análise da cartilha, observou-se que no texto, principalmente, mas também em algumas figuras, é utilizada a associação de vários conteúdos o que, segundo Zabala (2008) é relevante para incrementar a significância do conhecimento a ser aprendido. Os conteúdos mais frequentemente associados foram os atitudinais e os procedimentais, ou seja, o material educativo indicava qual comportamento deveria ser seguido, valorizado e reforçado, e quais ações ou conjunto de ações deveriam ser realizadas na prevenção.

O formato lúdico da cartilha, a linguagem coloquial dos personagens, a utilização de um protagonista com o qual as crianças e os pré-adolescentes podem se identificar, em associação com seus colegas de escola e bairro, de várias etnias, enfrentando situaçõesproblema que podem ser projetados no cotidiano do público alvo da campanha (infantojuvenil) também são elementos que contribuem para a aprendizagem dos conteúdos inseridos, conforme sugere Mendonça (2008).

A predominância de conteúdos atitudinais tanto para o texto como para as figuras, totalizando $70 \%$ dos conteúdos classificados, remete à Educação Sanitária, com enfoque na 
mudança de comportamentos, notadamente àqueles relacionados aos hábitos de higiene. Entretanto, deve-se destacar que os conteúdos atitudinais observados, em sua maioria, relacionam-se com a participação da comunidade como protagonista principal nas ações de combate à dengue, seja realizando a limpeza do domicílio, fazendo um mutirão para limpar e organizar a praça do bairro ou acionando os órgãos e/ou os agentes públicos para que tomem as medidas necessárias de acordo com sua competência.

Enquanto a comunidade, depois de mobilizada pela turma de protagonistas da história, passa, em sua maioria, a ter papel ativo no combate à dengue, os órgãos e os agentes públicos são retratados como parceiros da população (conteúdo conceitual), entretanto, em um papel passivo (conteúdo atitudinal), aguardando que um cidadão os acione para que possam executar ações que a população não conseguiu resolver sozinha ou para multar munícipes que não compreenderam sua função na saúde pública e, por exemplo, recusam-se a manter seu terreno limpo.

Anualmente as campanhas realizadas pelos órgãos gestores da saúde, nos estados e nos municípios, reforçam a importância da participação da comunidade nas ações de prevenção e combate à dengue, uma vez que ainda não existe vacina ou medicamentos antivirais. Dessa forma, as campanhas incidem sob o controle da proliferação do mosquito transmissor da doença, o Aedes aegypti, orientando a população através de campanhas focadas, principalmente, na manutenção do domicílio sempre limpo, eliminando os possíveis criadouros. Entretanto, segundo Lefèvre et al. (2004) esses tipos de campanhas apresentaram tímidos reflexos nos levantamentos entomológicos e não foram suficientes para promover mudanças de comportamento ou participação comunitária genuína.

O texto de apresentação da cartilha ("é de pequeno que se aprende" e "o objetivo é fazer com que as crianças sigam o exemplo do Maluquinho: mostrem aos pais a importância da prevenção") também remete à Educação Sanitária ao focar a ação nas crianças e adolescentes em idade escolar, para que esses transmitam o modelo a ser seguido - os comportamentos valorizados na campanha - para seus familiares. A distribuição das cartilhas nas escolas públicas, é outro elemento que remete à Educação Sanitária ao chamar a escola e os profissionais da educação para reforçarem comportamentos, hábitos e práticas de prevenção consideradas como fundamentais para o êxito de campanhas de saúde pública. 


\section{CONSIDERAÇÕES FINAIS}

Retomando a citação de Zabala (2008) - sobre a valorização de determinados conteúdos de aprendizagem, em detrimento de outros e em decorrência de um posicionamento ideológico do educador - e fazendo um paralelo com a Educação em Saúde, podemos perceber que alguns conteúdos da cartilha analisada refletem o ideário da Educação Sanitária, ainda que associados à participação e ao protagonismo da comunidade. Isso sugere que, mesmo incorporando as novas concepções sobre saúde e aproximando-se de elementos que reforçam o papel ativo da população na promoção da saúde e na prevenção de doenças, as ações educativas inseridas no material impresso em pauta permanecem arraigadas à relação entre saúde e modelagem de comportamento.

Passaram-se quatro décadas de campanhas contra a dengue e todos os anos são elaborados novos materiais, em diversas mídias, reforçando a importância de tampar as caixas d'água, manter os pratos dos vasos de plantas cheios de areia, os pneus tampados, as garrafas viradas de boca para baixo. Entretanto, o desafio continua sendo encontrar uma forma de fazer com que a população dê significado a essas ações, inserindo-as em seu cotidiano, apropriando-se delas, conscientes do por que o fazem e dos possíveis benefícios de sua ação para toda a comunidade.

O elemento lúdico, as imagens, as personagens e a linguagem coloquial utilizadas na história em quadrinhos podem contribuir para a significância dos conteúdos a serem aprendidos pelo leitor, entretanto, para verificar sua efetividade na mudança de comportamento das pessoas em prol das práticas de prevenção à dengue, seria relevante realizar um estudo que acompanhasse as crianças e suas famílias para investigar se aquelas realmente seguiram o modelo do protagonista da história e se suas famílias permitiram que elas desempenhassem o papel de modelo a ser seguido em casa.

\section{REFERÊNCIAS}

ARMINDO, G. L.; DINIZ, M. C. P.; SCHALL, V. T. Materiais educativos impressos sobre dengue: análise quali-quantitativa e reflexões sobre comunicação e educação em saúde. In: VIII ENCONTRO NACIONAL EM PESQUISA EM EDUCAÇÃO EM CIÊNCIAS, 2011, 
Campinas. Anais... Disponível em:

<http://www.nutes.ufrj.br/abrapec/viiienpec/resumos/R0288-1.pdf> Acesso em: 09 set. 2014.

ASSIS, S. S.; PIMENTA, D. N.; SCHALL, V. T. Materiais impressos sobre dengue: análise crítica e opiniões de profissionais de saúde e educação sobre seu uso. Revista Brasileira de Pesquisa em Educação em Ciências, Rio de Janeiro, v.13, n.3, 2013. Disponível em: <http://revistas.if.usp.br/rbpec/article/viewFile/281/348> Acesso em: 12 set. 2014.

BRASIL. Ministério da Saúde. Fundação Nacional de Saúde. Programa nacional de controle da dengue. Brasília, 2002. Disponível em:

<http://bvsms.saude.gov.br/bvs/publicacoes/pncd_2002.pdf>. Acesso em: 9 set. 2014.

Ministério da Saúde. Secretaria de Vigilância em Saúde. Departamento de Vigilância Epidemiológica. Diretrizes nacionais para prevenção e controle de epidemias de dengue. Brasília: Ministério da Saúde, 2009. Disponível em: <http://bvsms.saude.gov.br/bvs/publicacoes/diretrizes_nacionais_prevencao_controle_dengue .pdf>. Acesso em: 10 set. 2014.

Portal da Educação. 2014. Ministério da Educação. Programa nacional biblioteca da escola. Disponível em: $<$ http://portal.mec.gov.br/index.php?option=com_content\&view=article\&id=12368:programa -nacional-biblioteca-da-escola\&catid=309: programa-nacional-biblioteca-daescola\&Itemid=574>. Acesso em: 10 set. 2014.

Ministério da Saúde. Secretaria de Vigilância em Saúde. Departamento de Vigilância das Doenças Transmissíveis. Plano de contingência nacional para epidemias de dengue. Brasília, DF: Ministério da Saúde, 2015. Disponível em:

$<$ http://www.cve.saude.sp.gov.br/htm/zoo/pdf/ms15_plano-contingencia-dengue19jan15.pdf> Acesso em: 02 jul. 2015.

Ministério da Saúde. Secretaria de Vigilância de Saúde. Boletim Epidemiológico, v. 46, n. 18, 2015. Disponível em:

<http://portalsaude.saude.gov.br/images/pdf/2015/julho/06/2015-024---Dengue-SE-23.pdf> Acesso em: 02 jul. 2015.

CABELLO, K. S.A.; ROCQUE, L. L.; SOUZA, I.C.F. Uma história em quadrinhos para o ensino e divulgação da hanseníase. Revista Electrónica de Enseñanza de las Ciencias, Rio de Janeiro, v. 9, n. 1, p. 225-241, 2010. Disponível em:

<http://reec.uvigo.es/volumenes/volumen9/ART13_VOL9_N1.pdf>. Acesso em: 13 set. 2014.

CARUSO, F.; SILVEIRA, C. Quadrinhos para a cidadania. História, Ciências, SaúdeManguinhos, Rio de Janeiro, v. 16, n. 1, p. 217-236, mar. 2009. Disponível em: <http://www.scielo.br/scielo.php?script=sci_arttext\&pid=S010459702009000100013\&lng=pt\&nrm=iso > Acesso em: 10 jul. 2015. 
FREITAS, F. V.; REZENDE FILHO, L. A. Modelos de comunicação e uso de impressos na educação em saúde: uma pesquisa bibliográfica. Interface (Botucatu), Botucatu, v. 15, n. 36, p. 243-256, mar. 2011 . Disponível em:

<http://www.scielo.br/scielo.php?script=sci_arttext\&pid=S1414-

32832011000100019\&lng=en\&nrm=iso>. Acesso em: 08 set. 2015.

KAWAMOTO, E.M.; CAMPOS, L M.L. Histórias em quadrinhos como recurso didático para o ensino do corpo humano em anos iniciais do ensino fundamental. Ciência \& Educação, Bauru, v. 20, n. 1, p. 147-158, 2014. Disponível em:

<http://www.redalyc.org/articulo.oa?id=251030165009>. Acesso em: 14 set. 2014.

KELLY-SANTOS, A.; MONTEIRO, S. S.; ROZEMBERG, B. Significados e usos de materiais educativos sobre hanseníase segundo profissionais de saúde pública do município do Rio de Janeiro, Brasil. Cadernos de Saúde Pública, Rio de Janeiro, v.25, n.4, p.857-67, 2009. Disponível em: <http://www.scielo.br/scielo.php?script=sci_arttext\&pid=S0102311X2009000400017>. Acesso em: 08 set. 2014.

LEFÈVRE, A. M. C. et al. Representações sobre dengue, seu vetor e ações de controle por moradores do município de São Sebastião, litoral Norte do Estado de São Paulo,

Brasil. Cadernos de Saúde Pública, Rio de Janeiro, v. 23, n. 7, jul. 2007 . Disponível em: $<$ http://www.scielo.br/scielo.php?script=sci_arttext\&pid=S0102-

311X2007000700022\&lng=en\&nrm=iso>. Acesso em: 12 set. 14.

LEFÈVRE, F. et al. Representações sociais sobre relações entre vasos de plantas e o vetor da dengue. Revista de Saúde Pública, São Paulo, v. 38, n. 3, jun. 2004. Disponível em: $<$ http://www.scielo.br/scielo.php?script=sci_arttext\&pid=S003489102004000300011\&lng=en \&nrm=iso> Acesso em: 12 set. 2014.

MENDONÇA, M. R. S. Ciência em quadrinhos: recurso didático em cartilhas educativas. Recife, 2008. 223 f. Tese (Doutorado) -Universidade Federal de Pernambuco, 2008. Disponível em: <http://www.pgletras.com.br/2008/teses/tese-marciamendonca.pdf $>$. Acesso em: 10 set. 2014.

MIALHE, F. L.; SILVA, C. M. C. Estratégias para a elaboração de impressos educativos em saúde bucal. Arquivos em Odontologia, Belo Horizonte, v. 44, n 2, 2008. Disponível em: <http://www.fop.unicamp.br/biblioteca/artg/Arquivos\%20em\%20Odontologia\%2044(2)\%203 3-9.pdf>. Acesso em: 09 set. 2014.

NOGUEIRA, M. J.; MODENA, C. M.; SCHALL, V. T. Materiais educativos impressos sobre saúde sexual e reprodutiva utilizados na atenção básica em Belo Horizonte, MG: caracterização e algumas considerações. Revista Eletrônica de Comunicação, Informação e Inovação em Saúde, Rio de Janeiro, v. 3, n. 4, p. 169-79, 2009. Disponível em: <http://www.reciis.icict.fiocruz.br/index.php/reciis/article/view/727/pdf_164>. Acesso em: 02 jul. 2015. 
ORGANIZAÇÃO MUNDIAL DE SAÚDE (OMS). WHO Library Cataloguing-inPublication Data. First WHO report on neglected tropical diseases: working to overcome the global impact of neglected tropical diseases. Geneva, 2010. Disponível em: <http://www.who.int/neglected_diseases/2010report/en/>. Acesso em: 10 set. 2014.

PEREIRA, A. C. C. O uso de quadrinhos no ensino da matemática: um ensaio com alunos de licenciatura em matemática da UECE. In: X ENCONTRO NACIONAL DE EDUCAÇÃO MATEMÁTICA EDUCAÇÃO MATEMÁTICA, CULTURA E DIVERSIDADE. Salvador BA, 7 a 9 de Julho de 2010. Anais... Disponível em:

<http://www.gente.eti.br/lematec/CDS/ENEM10/artigos/RE/T18_RE1739.pdf>. Acesso em: 12 set. 2014.

REBERTE, L. M.; HOGA, L. A. K.; GOMES, A. L. Z. O processo de construção de material educativo para a promoção da saúde da gestante. Revista Latino-Americana de Enfermagem, Ribeirão Preto, v. 20, n.1, [08 telas], 2012. Disponível em:

<http://www.scielo.br/pdf/rlae/v20n1/pt_14> Acesso em: 26 jun. 2015.

REIS, D. C. Educação em saúde: aspectos históricos e conceituais. In: GAZZINELLI, M. F.; Reis, DC; Marques, RC. Educação em saúde: teoria, método e imaginação. Belo Horizonte, MG: Editora UFMG, 2006.

REIS T.C., FIGUEIREDO M.F.S., SOUZA e SOUZA L.P., SILVA J.R., AMARAL A.K.M., MESSIAS, R.B. et al. Educação em saúde: aspectos históricos no Brasil. Jornal of the Health Sciences Institute, São Paulo, v. 31, n. 2, p. 219-23, 2013. Disponível em:

<http://www.unip.br/comunicacao/publicacoes/ics/edicoes/2013/02_abrjun/V31_n2_2013_p219a223.pdf>. Acesso em: 09 set. 2014.

RENOVATO, R.D., BAGNATO, M.H.S. O Serviço Especial de Saúde Pública e suas ações de educação sanitária nas escolas primárias (1942-1960). Educar em Revista, Curitiba, Brasil, n. especial 2, p. 277-290, 2010.

RIO DE JANEIRO (Estado). Secretaria de Saúde. Maluquinhos contra a dengue 2. Secretaria de Saúde e Defesa Civil. Secretaria de Educação. Rio de Janeiro, 2008. Disponível em: $<$ http://www.riocontradengue.rj.gov.br/site/Conteudo/Material.aspx > Acesso em: 06 set. 2014.

ROCHA, H. H. P. Educação escolar e higienização da infância. Cadernos CEDES, Campinas, v. 23, n. 59, abr. 2003. Disponível em:

$<$ http://www.scielo.br/scielo.php?script=sci_arttext\&pid=S0101-32622003000100004\&

lng=pt\&nrm=iso $>$ Acesso em: 06 maio 2014.

VASCONCELOS, E. M. Educação popular: de uma prática alternativa a uma estratégia de gestão participativa das políticas de saúde. Physis, Rio de Janeiro, v. 14, n. 1, p. 67-83, jun. 
2014. Disponível em: <http://www.scielo.br/scielo.php?script=sci_arttext\&pid=S010373312004000100005\&lng=en\&nrm=iso>. Acesso em: 25 jun. 2015.

ZABALA, A. A prática educativa como ensinar. Tradução Hermani F. da F. Rosa. Porto Alegre, RS: Artmed, 2008.

ZOMBINI, E. V.; PELICIONI, M. C. F. Estratégias para a avaliação de um material educativo em saúde ocular. Revista brasileira de crescimento e desenvolvimento humano, São Paulo, v. 21, n.1, p. 51-58, 2011. Disponível em:

<www.revistas.usp.br/jhgd/article/download/19995/22081>. Acesso em: 26 jun. 2015. 